\title{
Trends in influenza vaccine coverage and vaccine hesitancy in Canada, 2006/07 to 2013/14: results from cross-sectional survey data
}

\author{
Sarah A. Buchan MSc, Jeffrey C. Kwong MD MSc
}

Abstract

Background: Past studies have reported influenza vaccination coverage below national targets, but up-to-date estimates are needed to understand trends and to identify areas for intervention. The objective of this study was to describe recent trends in influenza vaccination in Canada, timing of uptake and reasons for not receiving the vaccine.

Methods: We pooled data from the 2007 to 2014 cycles of the Canadian Community Health Survey. Using bootstrapped survey weights, we examined influenza vaccine coverage by various groups, including by age and by presence of chronic medical conditions.

Results: The overall sample included 481526 respondents. Across all survey cycles combined, $29 \%$ of respondents reported receiving seasonal influenza vaccination in the past 12 months. Coverage levels were fairly consistent during the study period, but varied by province or territory. Vaccination coverage decreased over time among those aged 65 years and older. Among those who received a vaccination, it was most common to do so in October or November. Among those not vaccinated, the most frequently cited reason was believing it was unnecessary.

Interpretation: Influenza vaccination coverage continues to fall below national targets, with substantial declines seen among those aged 65 years and older, a group for which vaccination is particularly important. More intensive efforts are needed to improve coverage in Canada, particularly for high-risk groups.

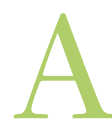

nnual influenza epidemics cause substantial mortality, morbidity, health care costs and lost economic productivity in Canada. ${ }^{1-3}$ Influenza vaccination is the most effective way to prevent infection. ${ }^{4}$ In 2001 , national influenza vaccine coverage targets were set at $80 \%$ for high-risk groups, specifically adults aged 65 years and older, and individuals with chronic medical conditions that increase the risk of complications from influenza infection. ${ }^{5}$ However, trends in influenza vaccination measured using nationally representative data up to 2005 demonstrated suboptimal coverage for high-risk groups; only those aged 75 years and older with chronic conditions reached the target. ${ }^{6}$ At a meeting of vaccination experts in 2005, a goal of $80 \%$ coverage by 2010 was again set for those aged 65 years and older and those aged 18-64 years with chronic medical conditions. ${ }^{5}$

An earlier study by Kwong and colleagues also examined the impact of the introduction of publicly funded universal influenza vaccination in Ontario in 2000. ${ }^{6}$ Many other prov- inces now provide universal influenza vaccination; by the 2013/14 influenza season, all provinces and territories except New Brunswick, Quebec and British Columbia had implemented comparable programs. ${ }^{7}$ Additionally, several provinces (Prince Edward Island, Nova Scotia, New Brunswick, Ontario, Manitoba, Saskatchewan, Alberta and British Columbia) have implemented policies allowing pharmacists to administer influenza vaccines to increase access to vaccination. So far, these policies have been associated with modest increases in vaccine coverage. ${ }^{8}$ The benefits of influenza vaccination for both individuals and populations depend on the

Competing interests: None declared.

This article has been peer reviewed.

Correspondence to: Jeffrey Kwong, jeff.kwong@utoronto.ca CMAJ Open 2016. DOI:10.9778/cmajo.20160050 
timing of vaccination (i.e., the month of vaccine receipt), particularly among high-risk groups. ${ }^{9-12}$ Because vaccination is most beneficial before epidemics start, early administration of influenza vaccines is recommended. ${ }^{4,13}$

Timely and reliable estimates of vaccine coverage are crucial for evaluating vaccination programs and for identifying groups with suboptimal coverage. Understanding the reasons for not receiving influenza vaccines can guide the allocation of additional resources to increase coverage. Therefore, the objectives of this study were to describe the most recent Canadian and provincial trends in influenza vaccination, to examine variations in the timing of influenza vaccination and to characterize reasons for not receiving influenza vaccines.

\section{Methods}

\section{Study population}

We used nationally representative data from the 2007 to 2014 cycles of the Canadian Community Health Survey. This cross-sectional survey has been conducted annually by Statistics Canada since 2007 through telephone and in-person interviews, and it covers a range of questions related to health status, health care use and health determinants. ${ }^{14}$ Using a multistage stratified cluster design, each cycle includes a sample of about 65000 respondents aged 12 years and older. The survey excludes people living on Aboriginal reserves, full-time members of the Canadian military, people in institutions and 2 remote health regions in Quebec (with all of these exclusions representing $<3 \%$ of the population). ${ }^{10}$ Response rates ranged from $65.6 \%$ to $77.6 \%$ across the cycles. ${ }^{14}$ The current study was approved by the Ethics Review Board of Public Health Ontario.

\section{Definitions}

The dependent variable was self-reported influenza vaccination within the past 12 months, determined through responses to the questions, "Have you ever had a (seasonal) flu shot?" and "When did you have your last (seasonal) flu shot?" Individuals reporting receipt of their last flu shot in the preceding 12 months were considered vaccinated. These respondents were also asked, "In which month did you have your last flu shot?" Those whose response matched the month of the survey date were then asked, "Was that this year or last year?" We considered respondents who reported receipt of influenza vaccine during the same month as the survey date but in the preceding year as not vaccinated.

To determine the presence of chronic medical conditions, respondents were asked whether they had been diagnosed by a health professional with asthma, chronic obstructive pulmonary disease (COPD), heart disease, stroke, diabetes or cancer; people with these conditions are recommended to receive influenza vaccination. ${ }^{4}$

Two sets of age groups were considered in this analysis: 1 ) $12-19,20-49,50-64,65-74$ and $75-84$ years, and 85 years and older; and 2) 12-49 and 50-64 years, and 65 years and older.

Risk groups were defined as high or low. Those deemed high risk were aged 65 years and older, or aged 12-64 years with at least 1 chronic condition. Individuals aged 12-64 years with no chronic conditions were considered low risk.

We defined universal influenza vaccination funding policies as provincial public funding for influenza vaccines for all residents aged 6 months and older. We defined pharmacist policies as having legislation permitting pharmacists to administer influenza vaccines. We set the start of these policies to coincide with the start of the corresponding influenza vaccination campaign, defined as Oct. 1.

Owing to small samples, the 3 territories were combined for certain analyses.

The definitions of education, household income, smoking status, body mass index, racial/cultural background, immigration status, marital status, rural residence, self-reported health, and having a regular doctor have been previously described. ${ }^{15,16}$

\section{Statistical analysis}

We pooled individual-level responses from all survey cycles. We used cross-tabulations to estimate the proportion of people who reported receipt of influenza vaccination in the past 12 months for: a) the overall population aged 12 years and older; b) various subgroups defined by sociodemographic characteristics, including province of residence; and c) risk groups for influenza vaccination. Analyses were repeated restricting to respondents who were surveyed between February and August. We also used cross-tabulations to compare the reasons that people who were not considered vaccinated reported for not receiving influenza vaccination. Reasons for not receiving the flu shot were examined by whether or not the respondent reported never having received a flu shot or if they had not received one in the last 12 months. We also examined the reasons for not receiving a flu shot by province, age group and presence of chronic conditions. Reported month of receipt of last influenza vaccination was also examined by season, risk group and province. We grouped those who reported receiving their vaccine between March and August owing to small numbers.

We used sampling weights to account for an unequal probability of selection in the sample. We calculated all estimates of coverage and coefficients of variation using bootstrap weights, with normalized weights used for tests between proportions due to large samples. All tests were 2 -sided and used a significance level of $p<0.05$. We compared estimates of coverage for the 2006/07 influenza season with those for the 2013/14 season, but only differences of 5 or more percentage points were considered to have public health relevance. We used SAS statistical software (version 9.4) for all analyses.

\section{Results}

\section{Trends in influenza coverage}

Across the 8 influenza seasons overall, 29\% of respondents reported receiving a seasonal influenza vaccine during the previous 12 months (Table 1; Appendix 1, available at www.cmajopen. $\mathrm{ca} /$ content/4/3/E455/suppl/DC1). The annual proportion vaccinated was fairly consistent throughout the study period, but the level was lowest during the 2009/10 influenza A/H1N1 pandemic. The 2010 survey cycle was the only one that included 
questions about the pandemic influenza vaccine. Of this cycle's respondents, $19 \%$ of respondents reported receiving both the pandemic and the seasonal vaccines, $52 \%$ reported receiving nei- ther vaccine, $24 \%$ received the pandemic vaccine but not the seasonal vaccine, and $5 \%$ received the seasonal vaccine but not the pandemic vaccine. Seasonal influenza vaccine coverage remained

\begin{tabular}{|c|c|c|c|c|c|c|c|c|c|c|}
\hline \multirow[b]{2}{*}{ Characteristic } & \multicolumn{10}{|c|}{$\%$ of respondents, $n=481526^{*}$} \\
\hline & Total & $2006 / 07$ & $2007 / 08$ & 2008/09 & $2009 / 10$ & $2010 / 11$ & $2011 / 12$ & $2012 / 13$ & $2013 / 14$ & Overall \\
\hline Overall & 100.0 & 32 & 30 & 30 & 26 & 28 & 28 & 28 & 31 & 29 \\
\hline \multicolumn{11}{|l|}{ Sex } \\
\hline Male & 49.0 & 29 & 26 & 27 & 23 & 25 & 24 & 25 & 27 & 26 \\
\hline Female & 51.0 & 35 & 33 & 33 & 28 & 31 & 31 & 30 & 34 & 32 \\
\hline \multicolumn{11}{|l|}{ Chronic conditions } \\
\hline$\geq 1$ & 22.5 & 51 & 47 & 47 & 42 & 45 & 45 & 45 & 47 & 46 \\
\hline Heart disease & 4.7 & 63 & 60 & 60 & 53 & 58 & 56 & 57 & 59 & 58 \\
\hline Stroke† & 1.0 & 61 & 55 & 54 & 53 & 50 & 55 & 55 & 46 & 53 \\
\hline Diabetes† & 6.1 & 61 & 57 & 57 & 50 & 57 & 54 & 54 & 55 & 55 \\
\hline Cancer & 1.9 & 55 & 56 & 53 & 56 & 59 & 53 & 49 & 54 & 54 \\
\hline Asthma & 8.2 & 40 & 37 & 37 & 34 & 35 & 35 & 34 & 38 & 36 \\
\hline COPD† & 2.2 & 67 & 60 & 58 & 48 & 55 & 58 & 54 & 55 & 55 \\
\hline None & 77.5 & 27 & 25 & 25 & 21 & 23 & 23 & 23 & 26 & 24 \\
\hline \multicolumn{11}{|l|}{ Income quartileł } \\
\hline Lowest† & 5.6 & 32 & 30 & 27 & 23 & 27 & 25 & 25 & 27 & 27 \\
\hline Lower-middle & 14.2 & 34 & 33 & 33 & 29 & 33 & 31 & 31 & 33 & 32 \\
\hline Upper-middle & 27.5 & 33 & 30 & 30 & 26 & 29 & 30 & 29 & 31 & 30 \\
\hline Highest & 44.2 & 30 & 28 & 28 & 24 & 27 & 26 & 26 & 30 & 27 \\
\hline \multicolumn{11}{|l|}{ Province or territory } \\
\hline $\begin{array}{l}\text { Newfoundland and } \\
\text { Labradort }\end{array}$ & 1.5 & 22 & 23 & 25 & 23 & 25 & 24 & 24 & 27 & 24 \\
\hline Prince Edward Island & 0.4 & 33 & 28 & 27 & 26 & 30 & 32 & 28 & 35 & 30 \\
\hline Nova Scotia† & 2.8 & 40 & 40 & 37 & 43 & 47 & 43 & 40 & 45 & 42 \\
\hline New Brunswick† & 2.2 & 28 & 30 & 28 & 32 & 36 & 34 & 35 & 37 & 33 \\
\hline Quebec & 23.4 & 25 & 25 & 25 & 16 & 21 & 22 & 22 & 24 & 22 \\
\hline Ontario & 39.1 & 37 & 34 & 34 & 27 & 31 & 29 & 30 & 33 & 32 \\
\hline Manitoba & 3.4 & 28 & 25 & 27 & 31 & 26 & 26 & 27 & 30 & 27 \\
\hline Saskatchewan & 2.9 & 27 & 28 & 28 & 26 & 30 & 30 & 25 & 30 & 28 \\
\hline Alberta & 10.8 & 28 & 26 & 29 & 29 & 29 & 27 & 27 & 31 & 28 \\
\hline British Columbia & 13.3 & 32 & 28 & 29 & 29 & 28 & 30 & 28 & 32 & 30 \\
\hline Yukon & 0.1 & 29 & 27 & 24 & 45 & 33 & 27 & 27 & 30 & 31 \\
\hline Northwest Territories & 0.1 & 35 & 33 & 30 & 33 & 39 & 36 & 29 & 35 & 34 \\
\hline Nunavut & 0.1 & 37 & 34 & 44 & 42 & 43 & 26 & 27 & 33 & 35 \\
\hline \multicolumn{11}{|c|}{ Presence of universal funding for influenza vaccines } \\
\hline Yes & 51.7 & 37 & 34 & 33 & 27 & 31 & 29 & 29 & 33 & 31 \\
\hline No & 48.3 & 28 & 27 & 28 & 24 & 24 & 25 & 25 & 27 & 26 \\
\hline $\begin{array}{l}\text { Note: COPD = chronic obst } \\
{ }^{*} \text { Representing } 27291380 \\
\dagger \text { Changed by } \geq 5 \text { percentag } \\
\ddagger 8.6 \% \text { did not report their ir }\end{array}$ & $\begin{array}{l}\text { ve pulm } \\
\text { adians. }\end{array}$ & ry disease & od. & 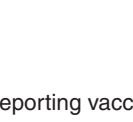 & 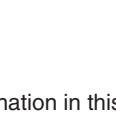 & 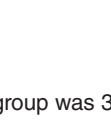 & 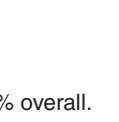 & & & \\
\hline
\end{tabular}


depressed for the initial 3 postpandemic seasons until returning close to prepandemic levels for the most recent (2013/14) season.

Females and older age groups consistently achieved higher coverage. Among the provinces and territories, Nova Scotia consistently achieved the highest coverage, which increased by $5 \%$ (from $40 \%$ in $2006 / 07$ to $45 \%$ in $2013 / 14$ ) during the study period. The greatest net increase was observed in New Brunswick, from $28 \%$ in $2006 / 07$ to $37 \%$ in $2013 / 14$. Whereas Quebec had the lowest coverage levels, Ontario experienced the greatest drop during the study period (from $37 \%$ to $33 \%)$. Coverage was higher in provinces that provide universal funding of influenza vaccines for their residents. Coverage was stable in all income groups except for the lowest quartile, for whom a drop from $32 \%$ to $27 \%$ was observed.

The results did not change when the analysis was restricted to those surveyed between February and August (data not shown).

\section{Coverage by risk group}

National vaccination coverage decreased $9 \%$ over time for individuals aged 65 years and older, with a drop of $11 \%$ for those aged 85 years and older (Figure 1). Substantial decreases in coverage were observed among those aged 65 years and older in all provinces and territories, except for Newfoundland and Labrador (Table 2). In those aged 12-64 years with a chronic medical condition, influenza vaccine coverage in most provinces remained relatively stable, but Ontario saw a significant decrease from $46 \%$ to $36 \%$ (Table 2). In the low-risk group, numerous provinces made significant gains in vaccination coverage over time, including Nova Scotia, New Brunswick, Manitoba, Saskatchewan and Alberta.

\section{Progress toward targets}

No group met the $80 \%$ target during the study period, including those at high risk (Figure 2). Those aged 85 years and older with a chronic condition were the closest to reaching this level $(74 \%)$. Since this target was reconfirmed in 2005 , coverage has declined and was even further from this level than in 2005 .

\section{Timing of influenza vaccination}

The most common month to receive influenza vaccination was November (48\%), followed by October (30\%). Few people reported being vaccinated in December $(7 \%)$, January (4\%), February (1\%), March-August (2\%) or September (3\%); $5 \%$ did not recall the month of vaccination. The percentage of people receiving influenza vaccines in October increased from $24 \%$ in $2006 / 07$ to $34 \%$ in $2013 / 14$, whereas those receiving influenza vaccines in November decreased $12 \%$ (from $55 \%$ to $43 \%$ ). Those aged 65 years and older had higher vaccine uptake in October than those at low risk $35 \%$ v. $27 \%, p<0.001)$.

\section{Reasons for not receiving influenza vaccination}

Across all groups, the most frequently reported reason for not receiving seasonal influenza vaccination was perceiving it to be unnecessary (Table 3). Eighty-three percent of people who had never received a flu shot thought it unnecessary, which is significantly higher than the $53 \%$ reported by those who had had a previous flu shot $(p<0.001)$. Residents of Quebec cited this reason most frequently, with $80 \%$ of those not having

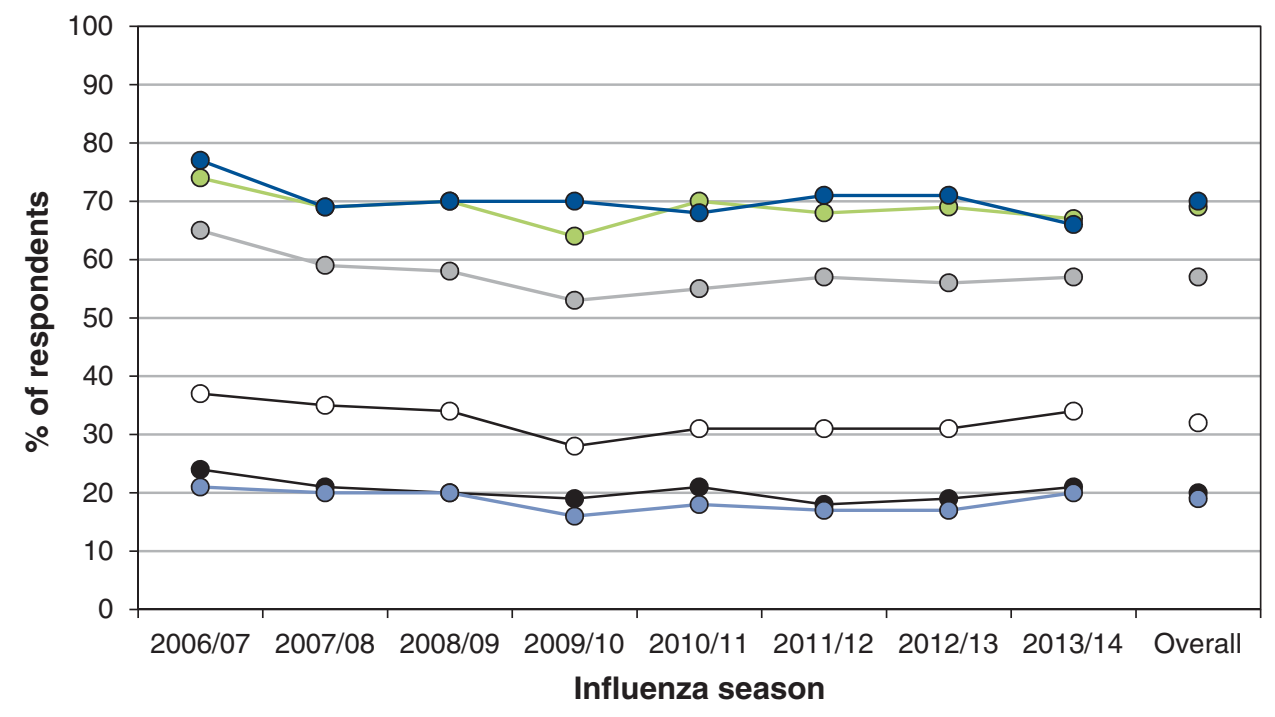

$\longrightarrow-12-19 \mathrm{yr} \longrightarrow-20-49 \mathrm{yr} \longrightarrow-0-50-64 \mathrm{yr} \rightarrow 0-65-74 \mathrm{yr} \longrightarrow \mathrm{O}-75-84 \mathrm{yr} \longrightarrow \mathrm{c} \longrightarrow \mathrm{yr}$

Figure 1: Percentage reporting influenza vaccination within the previous 12 months in the 2006/07 to $2013 / 14$ influenza seasons, by age group. Note: For age groups $65-74,75-84$ and $\geq 85$, values changed by $\geq 5$ percentage points during the study period. 


\section{Table 2: Respondents reporting influenza vaccination in the $2006 / 07$ to $2013 / 14$ influenza seasons, by risk group}

\begin{tabular}{|c|c|c|c|c|c|c|c|c|c|c|}
\hline \multirow[b]{2}{*}{ Variable } & \multicolumn{10}{|c|}{$\%$ of respondents } \\
\hline & Total & $2006 / 07$ & 2007/08 & 2008/09 & $2009 / 10$ & $2010 / 11$ & $2011 / 12$ & $2012 / 13$ & $2013 / 14$ & Overall \\
\hline \multicolumn{11}{|c|}{ High-risk group: aged $\geq 65 \mathrm{yr}$} \\
\hline Canada* $(n=74$ 491†) & 100.0 & 69 & 63 & 63 & 58 & 61 & 61 & 61 & 60 & 62 \\
\hline $\begin{array}{l}\text { Newfoundland and } \\
\text { Labrador }\end{array}$ & 1.6 & 52 & 51 & 51 & 55 & 51 & 53 & 50 & 56 & 52 \\
\hline Prince Edward Island* & 0.5 & 67 & 49 & 57 & 59 & 63 & 60 & 55 & 58 & 58 \\
\hline Nova Scotia* & 3.2 & 76 & 72 & 72 & 71 & 73 & 75 & 74 & 70 & 73 \\
\hline New Brunswick* & 2.4 & 64 & 59 & 57 & 62 & 65 & 66 & 61 & 59 & 62 \\
\hline Quebec*$^{*}$ & 25.1 & 63 & 59 & 58 & 37 & 52 & 53 & 55 & 54 & 54 \\
\hline Ontario* & 38.4 & 76 & 67 & 67 & 68 & 65 & 67 & 67 & 66 & 67 \\
\hline Manitoba* & 3.5 & 66 & 64 & 60 & 68 & 59 & 56 & 61 & 56 & 61 \\
\hline Saskatchewan* & 3.1 & 61 & 62 & 61 & 58 & 61 & 59 & 53 & 50 & 58 \\
\hline Alberta* & 8.3 & 70 & 60 & 59 & 58 & 65 & 56 & 60 & 58 & 60 \\
\hline British Columbia* & 13.9 & 67 & 60 & 61 & 62 & 59 & 63 & 60 & 60 & 61 \\
\hline Territories $¥$ & 0.1 & 76 & 74 & 66 & 69 & 68 & 57 & 56 & 63 & 65 \\
\hline \multicolumn{11}{|c|}{ High-risk group: aged 12-64 yr with at $\geq 1$ chronic condition } \\
\hline Canada $(n=71366 \dagger$ ) & 100.0 & 39 & 36 & 35 & 32 & 34 & 33 & 32 & 36 & 34 \\
\hline $\begin{array}{l}\text { Newfoundland and } \\
\text { Labrador }\end{array}$ & 1.7 & 34 & 28 & 34 & 30 & 33 & 28 & 29 & 34 & 31 \\
\hline Prince Edward Island & 0.5 & 37 & 39 & 32 & 32 & $36 \S$ & $36 \S$ & $29 \S$ & 38 & 35 \\
\hline Nova Scotia & 3.4 & 48 & 55 & 49 & 58 & 56 & 47 & 57 & 52 & 53 \\
\hline New Brunswick & 2.5 & 40 & 39 & 32 & 43 & 47 & 35 & 42 & 44 & 40 \\
\hline Quebec & 23.5 & 31 & 31 & 31 & 23 & 25 & 30 & 26 & 30 & 28 \\
\hline Ontario* & 39.1 & 46 & 39 & 39 & 31 & 36 & 33 & 35 & 36 & 36 \\
\hline Manitoba & 3.5 & 34 & 32 & 36 & 42 & 35 & 29 & 30 & 30 & 33 \\
\hline Saskatchewan & 2.8 & 32 & 37 & 32 & 36 & 27 & 37 & 27 & 36 & 33 \\
\hline Alberta & 10.8 & 35 & 33 & 32 & 33 & 36 & 33 & 30 & 37 & 34 \\
\hline British Columbia & 11.9 & 39 & 36 & 33 & 36 & 35 & 35 & 30 & 39 & 35 \\
\hline Territoriesł & 0.3 & 38 & 36 & $32 \S$ & 47 & 40 & 37 & 30 & 37 & 37 \\
\hline \multicolumn{11}{|c|}{ Low-risk group: aged 12-64 yr with no chronic conditions } \\
\hline Canada ( $n=335699 \dagger)$ & 100.0 & 23 & 21 & 22 & 17 & 20 & 19 & 19 & 22 & 20 \\
\hline $\begin{array}{l}\text { Newfoundland and } \\
\text { Labrador }\end{array}$ & 1.5 & 14 & 16 & 17 & 14 & 16 & 16 & 16 & 17 & 16 \\
\hline Prince Edward Island & 0.4 & 24 & 20 & 19 & 16 & 20 & 24 & 20 & 28 & 21 \\
\hline Nova Scotia* & 2.6 & 29 & 28 & 25 & 32 & 38 & 32 & 26 & 35 & 31 \\
\hline New Brunswick* & 2.1 & 17 & 21 & 20 & 22 & 26 & 25 & 25 & 29 & 23 \\
\hline Quebec & 23.0 & 16 & 17 & 16 & 10 & 13 & 12 & 13 & 14 & 14 \\
\hline Ontario & 39.3 & 28 & 26 & 26 & 17 & 22 & 20 & 20 & 24 & 23 \\
\hline Manitoba* & 3.4 & 18 & 15 & 18 & 19 & 17 & 18 & 18 & 23 & 18 \\
\hline Saskatchewan* & 2.8 & 18 & 18 & 20 & 16 & 23 & 22 & 18 & 24 & 20 \\
\hline Alberta* & 11.3 & 20 & 19 & 23 & 23 & 22 & 21 & 21 & 25 & 22 \\
\hline British Columbia & 13.4 & 23 & 21 & 21 & 21 & 19 & 21 & 21 & 23 & 21 \\
\hline Territories $\ddagger$ & 0.3 & 29 & 26 & 28 & 36 & 34 & 27 & 24 & 29 & 29 \\
\hline
\end{tabular}


received influenza vaccination in the past 12 months deeming it unnecessary. The reported reasons were consistent over the study period. The only change in reasons was for those who had previously received their influenza vaccination but had not done so in the past 12 months, with $49 \%$ in this group thinking it unnecessary in 2006/07 and 54\% in 2013/14.

\section{Interpretation}

Seasonal influenza vaccine coverage in Canada was essentially stable between the 2006/07 and 2013/14 influenza seasons, except for a dip during the $2009 \mathrm{~A} / \mathrm{H} 1 \mathrm{~N} 1$ pandemic that required a few influenza seasons to recover from. Although seasonal influenza vaccine coverage dipped slightly in the pandemic year, overall coverage for any influenza vaccine (i.e., either the seasonal trivalent vaccine or the pandemic monovalent vaccine) was highest for that year, likely due to the pandemic situation and messaging about the additional need for vaccination. Surprisingly, we observed a substantial drop in coverage over time among those aged 65 and older, with an even larger drop among those aged 85 and older. Coverage also declined among individuals younger than 65 years with chronic conditions, another high-risk group, although this trend was observed only in a few provinces. Consequently, the level of vaccine coverage in Canada is even further from the target of $80 \%$ for high-risk groups set in 2005. Individuals with asthma comprised a substantial proportion of those with chronic conditions, and they had the lowest coverage; further efforts to target this group could result in overall gains among high-risk groups. Whereas coverage dropped for high-risk age groups, gains were seen in the low-risk population in some provinces. We also observed variations in coverage by sex, age group, risk group and province. Variations across provinces may be partially due to differences in vaccination policies, such as universal funding for influenza vaccines or the ability of pharmacists to administer vaccines. ${ }^{8,15}$

The most frequently cited reason for not receiving seasonal influenza vaccination was perceiving it to be unnecessary, and this was consistent across risk groups and provinces. However, the proportion citing this reason was lower in those classified as having a chronic condition.

Coverage estimates in selected countries were higher than in Canada for the 2013/14 season (Table 4). In the United States, for example, vaccination coverage was higher among those aged 65 years and older, with $65 \%$ coverage obtained; this estimate, however, still falls below the US national target of $70 \% \cdot{ }^{17}$ Few countries have met their targets for this group. Countries such as the Netherlands, which has attained the highest coverage in Europe in past seasons, might be able to offer strategies to increase uptake in Canada. ${ }^{21}$ Other trends noted in Canada were also observed in the US, such as relatively stable coverage across time and the greatest proportion of vaccinations being provided in October and November. ${ }^{17}$ Large variability in coverage between states has been reported in the US and in Australia. The Australian Adult Vaccination Survey also reported similar results regarding reasons for not being vaccinated, with

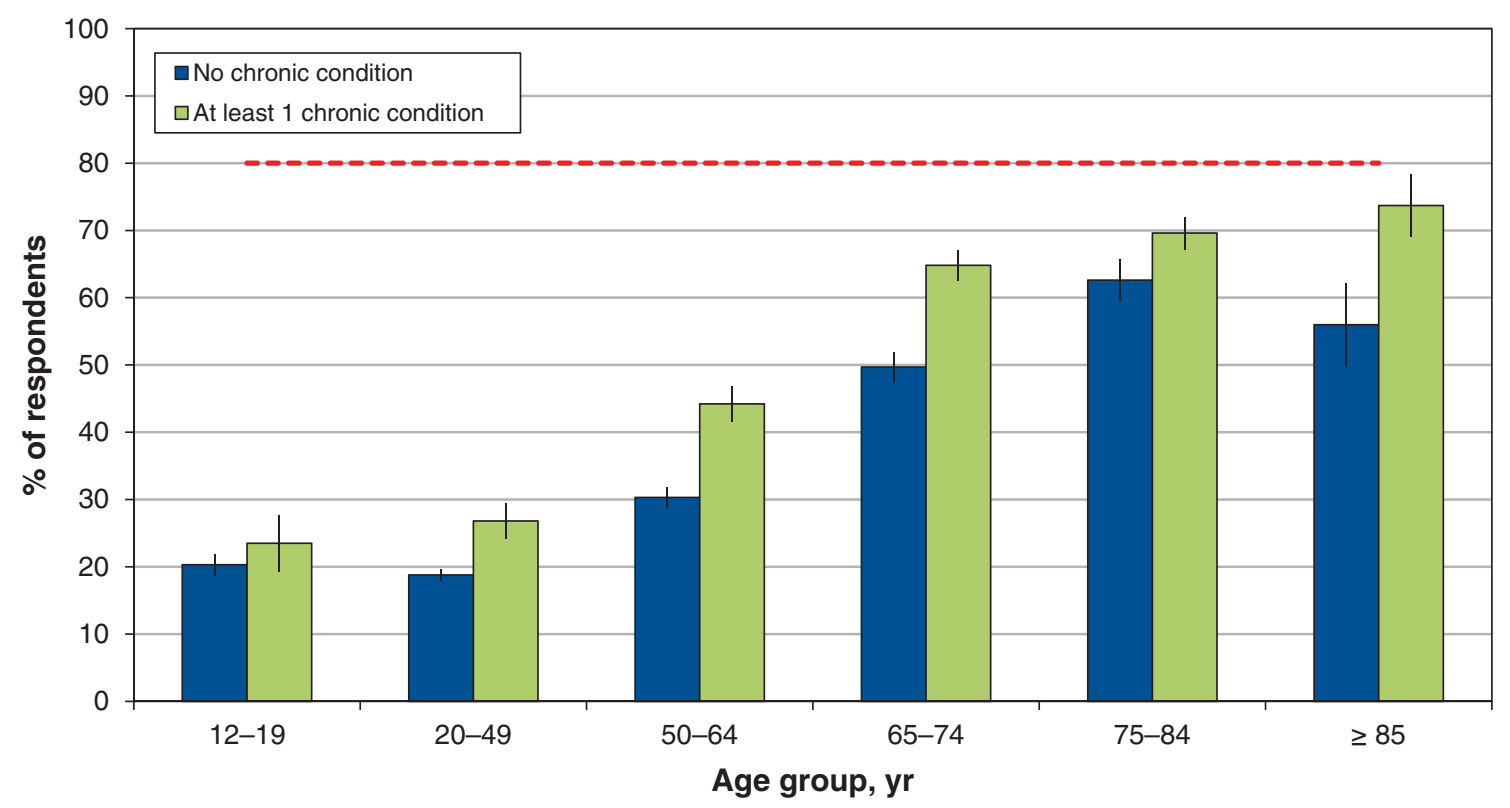

Figure 2: Percentage reporting influenza vaccination during the 2013/14 influenza season, by age group and presence of chronic conditions. Red dashed line represents target set in 2010 for adults aged $\geq 65$ years and those with chronic conditions. 
the first 2 reasons being that the respondent does not get the flu or is not at risk, followed by not getting around to it; these responses echo those reported in Canada. ${ }^{22}$ In this study, perceiving influenza vaccines to be unnecessary was the main reason reported for not receiving seasonal influenza vaccination across all characteristics examined, including risk group; this was true for both those who have never received a flu shot and for those who have had one in the past but not in the last 12 months. Further work is needed to explore why individuals believe the influenza vaccination is unnecessary, so that efforts to tackle this barrier to vaccination can be made. This may include enhanced education and discussion by health care providers. ${ }^{23}$ Additional efforts to enhance vaccination access, increase community demand, and improve provision by providers or the health care system may also improve coverage. ${ }^{24,25}$

The conclusions from our study are similar to those of a recently published report, ${ }^{26}$ although our study differed slightly by reporting coverage by influenza season (as opposed to survey cycle) and using a stricter definition for influenza vaccination. This study updates previous work on trends in influenza vaccination, using data after the survey was conducted annually, as opposed to every 2 years.

\section{Limitations}

This study has some limitations. The Canadian Community Health Survey does not include children younger than 12 years or older adults in institutions, both important risk groups who should be vaccinated. Additionally, we relied on self-reports to assess vaccine coverage. However, this outcome has been frequently used in influenza vaccination reporting and has been shown to be valid. ${ }^{27-36}$ There may be some recall bias regarding the receipt of seasonal influenza vaccination in the last 12 months, but this was partially mitigated by incorporating the follow-up questions regarding timing of vaccination into our outcome definition. The crosssectional nature of the data also limits our ability to make conclusions about temporal associations between predictors and vaccination status.

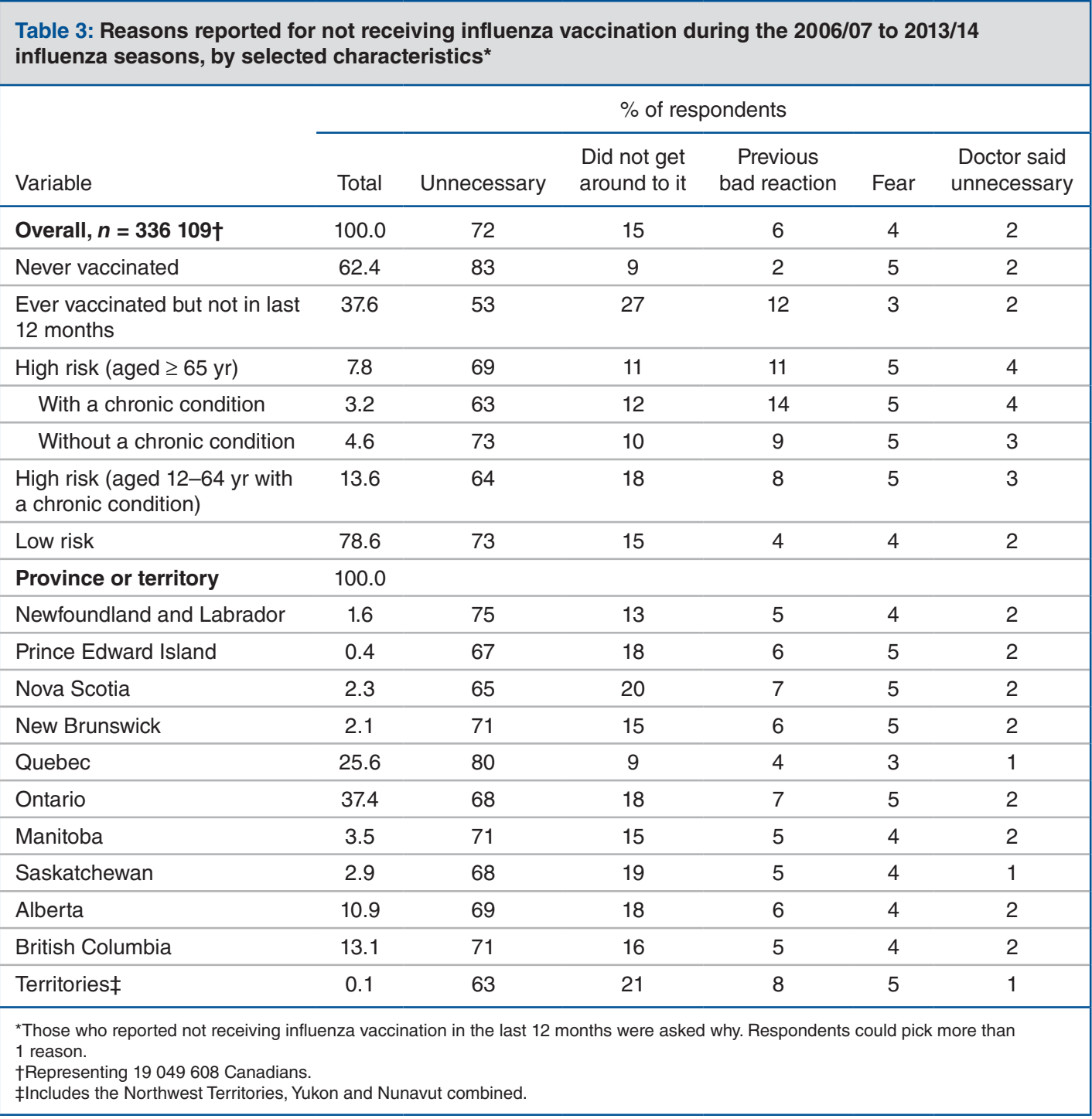




\begin{tabular}{|c|c|c|}
\hline \multicolumn{3}{|c|}{$\begin{array}{l}\text { Table 4: Comparison of influenza } \\
\text { vaccination coverage in } 2013 / 14 \text { in all } \\
\text { respondents and those aged } 65 \text { and } \\
\text { older, by country }\end{array}$} \\
\hline \multirow[b]{2}{*}{ Country } & \multicolumn{2}{|c|}{$\%$ of respondents } \\
\hline & Overall $^{*}$ & Age $\geq 65 \mathrm{yr}$ \\
\hline Canada & 31 & 60 \\
\hline United States $^{17}$ & 42 & 65 \\
\hline England $^{18}$ & NR & 73 \\
\hline Scotland ${ }^{18}$ & NR & 77 \\
\hline Australia $^{19}$ & 39 & 73 \\
\hline New Zealand ${ }^{20}$ & $\mathrm{NR}$ & 68 \\
\hline \multicolumn{3}{|c|}{$\begin{array}{l}\text { Note: } N R=\text { not reported. } \\
{ }^{*} \text { Age } \geq 12 \text { yr in Canada; age } \geq 18 \mathrm{yr} \text { in the United } \\
\text { States and Australia. }\end{array}$} \\
\hline
\end{tabular}

\section{Conclusion}

Seasonal influenza vaccine coverage remains below national targets and is lower than in 2005. Of particular concern is the drop in coverage observed in those aged 65 and older and the perception that influenza vaccination is unnecessary. Targeted efforts are needed to restore high coverage in high-risk groups.

\section{References}

1. Schanzer DL, Tam TWS, Langley JM, et al. Influenza-attributable deaths, Canada 1990-1999. Epidemiol Infect 2007;135:1109-16.

2. Schanzer DL, Zheng H, Gilmore J. Statistical estimates of absenteeism attributable to seasonal and pandemic influenza from the Canadian Labour Force Survey. BMC Infect Dis 2011;11:90.

3. Schanzer DL, McGeer A, Morris K. Statistical estimates of respiratory admissions attributable to seasonal and pandemic influenza for Canada. Influenza Other Respir Viruses 2013;7:799-808.

4. Statement on seasonal influenza vaccine for 2015-2016 [report]. Ottawa: Public Health Agency of Canada; 2015.

5. Final report of outcomes from the National Consensus Conference for Vaccine-Preventable Diseases in Canada. Can Commun Dis Rep 2008;33S2: $1-56$.

6. Kwong JC, Rosella LC, Johansen H. Trends in influenza vaccination in Canada, 1996/1997 to 2005. Health Rep 2007;18:9-19.

7. Public funding for influenza vaccination by province/territory (as of March 2016) [table]. Ottawa: Public Health Agency of Canada; 2005; Available: http:// healthycanadians.gc.ca/healthy-living-vie-saine/immunization-immunisation/ schedule-calendrier/influenza-vaccination-grippe-eng.php (updated 2016 May 3; accessed 2016 Mar. 10).

8. Buchan SA, Rosella LC, Finkelstein M, et al. Impact of pharmacist administration of influenza vaccines on uptake in Canada. CMA72016 Aug 8. [Epub ahead of print]

9. Monto AS. Seasonal influenza and vaccination coverage. Vaccine 2010;28(Suppl 4):D33-44.

10. Myers ER, Misurski DA, Swamy GK. Influence of timing of seasonal influenza vaccination on effectiveness and cost-effectiveness in pregnancy. Am $\mathcal{J}$ Obstet Gynecol 2011;204(Suppl 1):S128-40.

11. Lee BY, Bartsch SM, Brown ST, et al. Quantifying the economic value and quality of life impact of earlier influenza vaccination. Med Care 2015;53:218-29.

12. Chodick G, Heymann AD, Green MS, et al. Late influenza vaccination is associated with reduced effectiveness. Prev Med 2006;43:71-6.

13. Grohskopf LA, Sokolow LZ, Olsen SJ, et al. Prevention and control of influenza with vaccines: recommendations of the Advisory Committee on Immunization Practices, United States, 2015-16 influenza season. MMWR Morb Mortal Wkly Rep 2015;64:818-25.

14. Canadian Community Health Survey - annual component (CCHS). Ottawa: Statistics Canada; 2016. Available: www23.statcan.gc.ca/imdb/p2SV.pl?Function= getInstanceList\&Id=238854 (accessed 2016 Jan. 11).

15. Kwong JC, Sambell C, Johansen H, et al. The effect of universal influenza immunization on vaccination rates in Ontario. Health Rep 2006;17:31-40.

16. Quach S, Hamid JS, Pereira JA, et al. Influenza vaccination coverage across ethnic groups in Canada. CMAJ 2012;184:1673-81.
17. Flu vaccination coverage: United States, 2013-14 influenza season [report]. Atlanta: Centers for Disease Control and Prevention; 2014. Available: www.cdc.gov/flu/ pdf/fluvaxview/vax-coverage-1314estimates.pdf (updated 2016 Jan. 26; accessed 2016 Mar. 2).

18. Surveillance of influenza and other respiratory viruses in the United Kingdom: Winter 2013/14 [report]. Newspoll: Australia; 2014. Available: www.gov.uk/ government/uploads/system/uploads/attachment_data/file/325203/Flu_annual report_June_2014.pdf (accessed 2016 June 7).

19. Newspoll Omnibus Survey, Zune 2014: summary report: flu vaccinations [report]. 2014 June 23. Available: www.immunise.health.gov.au/internet/immunise/ publishing.nsf/Content/762A8FB9101D1759CA257D49002227B6/\$File/summ -report-flu-vaccinations-survey2014.pdf (accessed 2016 June 7).

20. Surveillance report: influenza surveillance in New Zealand 2014 [report]. Wellington (New Zealand): Institute of Environmental Science and Research; 2015. Available: https://surv.esr.cri.nz/PDF_surveillance/Virology/FluAnnRpt/ Influenzasurveillance2014Final.pdf (accessed 2016 June 7).

21. Mereckiene J, Cotter S, Nicoll A, et al. Seasonal influenza immunisation in Europe. Overview of recommendations and vaccination coverage for three seasons: pre-pandemic (2008/09), pandemic (2009/10) and post-pandemic (2010/11). Euro Surveill 2014;19:20780.

22. 2009 Adult Vaccination Survey: summary results. Canberra (Australia): Australian Institute of Health and Welfare; 2011. Available: www.aihw.gov.au/WorkArea/ DownloadAsset.aspx?id=10737418286 (accessed 2016 Mar. 2).

23. Johnson DR, Nichol KL, Lipczynski K. Barriers to adult immunization. Am 7 Med 2008;121(Suppl 2):S28-35.

24. Shefer A, Briss P, Rodewald L, et al. Improving immunization coverage rates: an evidence-based review of the literature. Epidemiol Rev 1999;21:96-142.

25. Thomas RE, Lorenzetti DL. Interventions to increase influenza vaccination rates of those 60 years and older in the community. Cochrane Database Syst Rev 2014; (7):CD005188.

26. Gionet L. Health at a glance: flu vaccination rates in Canada. Ottawa: Statistics Canada; 2015. Cat no 82-624-X.

27. Johansen H, Sambell C, Zhao W. Health Reports. Flu shots: National and provincial/territorial trends. Health Rep 2006;17:43-8.

28. Johansen H, Nguyen K, Mao L, et al. Influenza vaccination. Health Rep 2004; 15:33-43.

29. Mac Donald R, Baken L, Nelson A, et al. Validation of self-report of influenza and pneumococcal vaccination status in elderly outpatients. Am 7 Prev Med 1999;16:173-7.

30. Hutchison BG. Measurement of influenza vaccination status of the elderly by mailed questionnaire: response rate, validity and cost. Can 7 Public Health 1989;80:271-5.

31. Martin LM, Leff M, Calonge N, et al. Validation of self-reported chronic conditions and health services in a managed care population. Am 7 Prev Med 2000;18:215-8.

32. Zimmerman RK, Raymund M, Janosky JE, et al. Sensitivity and specificity of patient self-report of influenza and pneumococcal polysaccharide vaccinations among elderly outpatients in diverse patient care strata. Vaccine 2003;21:1486-91.

33. Skull SA, Andrews RM, Byrnes GB, et al. Validity of self-reported influenza and pneumococcal vaccination status among a cohort of hospitalized elderly inpatients. Vaccine 2007;25:4775-83.

34. Rolnick SJ, Parker ED, Nordin JD, et al. Self-report compared to electronic medical record across eight adult vaccines: Do results vary by demographic factors? Vaccine 2013;31:3928-35.

35. Mangtani P, Shah A, Roberts JA. Validation of influenza and pneumococcal vaccine status in adults based on self-report. Epidemiol Infect 2007;135:139-43.

36. Irving SA, Donahue JG, Shay DK, et al. Evaluation of self-reported and registrybased influenza vaccination status in a Wisconsin cohort. Vaccine 2009;27:6546-9.

Affiliations: Dalla Lana School of Public Health (Buchan, Kwong), University of Toronto; Institute for Clinical Evaluative Sciences (Kwong); Department of Family and Community Medicine (Kwong), University of Toronto, Toronto, Ont.

Contributors: Both authors conceptualized and designed the study, interpreted the results and drafted the manuscript. Sarah Buchan performed the analyses. Both authors gave final approval of the version to be published and agreed to act as guarantors of the work.

Acknowledgements: Sarah Buchan's doctoral training is supported by a Canadian Immunization Research Network Trainee Award. Jeffrey Kwong is supported by a New Investigator Salary Award from the Canadian Institutes of Health Research and a Clinician Scientist Award from the University of Toronto Department of Family and Community Medicine. The authors thank David Haans and Joanna Jacob at the Statistics Canada Research Data Centre, University of Toronto, for their support and guidance.

Supplemental information: For reviewer comments and the original submission of this manuscript, please see www.cmajopen.ca/content $/ 4 / 3$ / E455/suppl/DC1. 